\title{
TEOLOGIA E LITERATURA: BASES PARA UM DIÁLOGO
}

\author{
THEOLOGY AND LITERATURE: BASIS FOR A DIALOGUE
}

\author{
ANTONIO MANZATTO ${ }^{(*)}$
}

\begin{abstract}
RESUMO
A presente comunicação visa apresentar as linhas gerais do trabalho realizado pelo Grupo de Pesquisa em Literatura, Religião e Teologia (LERTE - PUC SP) e indica brevemente como o estudo das relações entre teologia e literatura tem-se intensificado nos últimos tempos, sobretudo em trabalhos realizados na zona de confluência entre as realidades literárias e religiosas. Trabalha-se mais relacionando a literatura, e a arte em geral, com religião que propriamente com a teologia, alguns encarando a confessionalidade da teologia como um impedimento para um diálogo frutuoso entre elas. Será preciso, então, esclarecer os pontos sobre os quais se baseia o trabalho teológico de aproximação com o universo literário, bem como o porquê de tal empreendimento. O presente texto parte da convicção, básica para a teologia e a fé cristã, de que Deus se revela na história da humanidade, e daí argumenta em favor de uma compreensão ampla da questão, no sentido de que tal Revelação nos chega através de histórias narradas sobre figuras de humanidade com densidade literária. Com isso visa estabelecer uma ponte real entre literatura e teologia, afirmando aspectos epistemológicos no horizonte da teologia que demonstram seu real interesse em dialogar com a literatura. Tais aspectos enfatizam a interpretação da história feita pelas narrativas e a perspectiva de humanidade que nelas se faz presente, propondo à teologia caminhos promissores para a reflexão que quer compreender melhor a Deus que é afirmado pela confissão de fé.
\end{abstract}

PALAVRAS ChAVE: Teologia e literatura. Narratividade. Revelação. Método antropológico.

\begin{abstract}
This paper aims to present some broad work lines by the Research Group in Literature, Religion and Theology (LERTE - PUC SP). The study of the relationship between theology and literature has intensified in recent times, especially in works at the dividing line between the literary and religious realities. Work more relating literature, and art in general, with religion than theology itself, some people thinking the cofessionalidade of theology as an impediment to a fruitful dialogue between them. We must then clarify the points on which is based the theological approach to the literary world, as well why work in this way. The present text starts with the conviction, basic to the theology and the Christian faith, that God reveals himself in human history, and then argues for a comprehensive understanding of the question, in the sense that such revelation comes to us through narrated stories on human figures with literary density. With that aims to establish a real bridge between literature and theology, stating epistemological aspects, in the horizon of the theology, showing its real interest in dialogue with the literature. These aspects emphasize the interpretation of history made by the narratives, and the prospect of humanity thtat is presente in them, proposing to theology promising paths for the reflection that wants to understand God better, he that is stated by the confession of faith
\end{abstract}

KEYWORDS: Theology and literature. Narrative. Revelation. Anthropological method.

${ }^{(*)}$ Doutor em teologia pela Universidade Católica de Lovaina, Bélgica. Atualmente é professor titular de teologia sistemática na Faculdade de Teologia da Pontifícia Universidade Católica de São Paulo, onde atua no curso de graduação e no Programa de Pós-Graduação em Teologia. Email: amanzatto@pucsp.br 


\section{INTRODUÇÃO}

O diálogo entre teologia e literatura tem sido incentivado nos últimos anos por estudos que se fazem sobre a interface deste relacionamento. Tanto no campo da literatura quanto no campo da teologia, e das ciências da religião de maneira ainda mais sensível, tais estudos se multiplicam explorando este campo que se constituiu há não muito tempo atrás. Embora encontremos traços desta relação em épocas passadas, mais recentemente é que as possibilidades desta inter-relação foram sendo perscrutadas, analisadas, estudadas. Não obstante este relativo pouco tempo de trabalho, o diálogo entre elas se revelou mais do que promissor e já existem frutos que podem ser percebidos aqui e ali.

Do ponto de vista do interesse levantado pela temática que ocasiona tais estudos está o fato evidente de sua novidade. Todo novo campo de trabalho suscita interesse que até então não existia. E se traz resultados interessantes, novos estudos se elaboram e a cadeia de trabalho vai-se constituindo. Redes de contato e de pesquisadores vão se edificando, a bibliografia se multiplica, congressos se realizam e grupos de trabalho são constituídos um pouco em muitos lugares ${ }^{1}$. De um lado o interesse pela temática, então, e de outro os resultados promissores, frutos do trabalho de quem atua neste campo de estudo praticamente inexplorado.

Os MÉTODOS

Neste contexto não é de se estranhar que apareçam vários métodos que procuram estudar de maneira adequada a teologia e a literatura em sua relação. Conhecemos vários deles e, ainda uma vez, cabe ressaltar que é positiva sua multiplicidade em função da abrangência e da diversidade do tema e dos objetivos perscrutados. Teopoética, correlação, estudos comparados, perspectiva mística, método antropológico e outros mais são maneiras de estudar a relação entre um e outro segundo aquilo que se busca ressaltar ou conhecer. Não há uma única maneira de fazer dialogar teologia e literatura e elas, que são plurais em suas maneiras de ser isoladamente, dão origem a relações plurais entre si. Por isso as metodologias de abordagem precisam permanecer diversas e múltiplas, e é bom que assim seja ${ }^{2}$.

\footnotetext{
${ }^{1}$ Veja-se YUNES, E. O que é a ALALITE?. Teoliterária 2 (2011), pp. 206-208; ou ainda YUNES, E; ROCHA, A; CARVALHO G. (Orgs.), Teologias e Literaturas: considerações metodológicas; São Paulo: Fonte Editorial, 2011.

2 MANZATTO, A. Pequeno panorama de teologia e literatura. In: MARIANI, C.B.; VILHENA, M.A, (Orgs.), Teologia e arte. São Paulo: Paulinas, 2010, p. 87-98.
} 
Resta, no entanto, a convicção de que a literatura fala do humano, sempre e qualquer que seja sua forma de elaboração, e por isso a referência a ela é necessária quando se quer conhecer melhor o que é o ser humano, procedimento que é próprio das ciências, aí incluindo a teologia ou as ciências da religião. A literatura não conhece o humano de maneira quantitativa, como acontece com outras áreas do conhecimento, mas o afirma e a ele se refere sempre. É uma forma de afirmar e conhecer o humano.

\section{O DIÁLOGO}

É exatamente esta sua característica que atrai o interesse da teologia e estabelece o diálogo entre elas. Para conhecer o humano há o terreno das diversas ciências, mormente as ciências humanas, que descrevem, analisam e quantificam as diversas formas de o humano ser no mundo e nele se manifestar. E há também o terreno das artes, com especial destaque para a literatura. Já se disse em outros lugares ${ }^{3}$ que o ponto de diálogo entre teologia e literatura, o terreno comum estendido entre elas é o humano ou, em vocabulário próprio, o antropológico. O interesse de uma e de outra, da literatura e da teologia, é o conhecimento, a afirmação e a compreensão do que significa ser humano no mundo. Cada uma, com o que lhe é característico, contribui para isso em diálogo com a outra e com os outros campos de conhecimento.

Por sua preocupação e envolvimento com o humano, a literatura não esquece a dimensão religiosa simplesmente porque esta é uma situação de humanidade. Daí as referências ao absoluto, a Deus ou ao sagrado presente em seus textos, em prosa e verso. Não se trata de necessariamente afirmar verdades doutrinais, no sentido de se comportar como veículo de transmissão de uma mensagem, mas sim de situar o humano em sua vida com referências a comportamentos, práticas e crenças religiosas que são, elas, componentes do existir humano ${ }^{4}$.

Assim, para falar da religião, do religioso e de suas crenças, a literatura não tem necessidade de deixar seu campo específico de atuação. É em sendo literatura que ela manifesta a situação humana envolta em dimensão de

\footnotetext{
3 Assim MANZATTO, A. Teologia e literatura. São Paulo: Loyola, 1994; também TOUTIN, A. Teologia y literatura: Hitos para um diálogo; Anales de la Facultad de Teologia 3; Suplementos a Teologia y Vida; Santiago: Pontifícia Universidad Católica de Chile, 2011.

4 Assim ELIADE, M. O sagrado e o profano. A essência das religiões. São Paulo: Martins Fontes, 1992; ainda OTTO, R. O sagrado, os aspectos irracionais do divino e sua relação com o racional. São LeopoldoPetrópolis: Sinodal-Vozes, 2007.
} 
religiosidade. Pode ou não evoluir para conteúdos de teologia, e não é necessário que o faça para interessar a ela porque a questão não é se perguntar pela teologia da obra ou de seu autor, mas pela compreensão de ser humano que a obra apresenta e, por este caminho, elaborar uma reflexão teológica que lhe seja fiel e pertinente.

Talvez esta seja uma das razões de tais estudos privilegiarem, na verdade, o diálogo entre literatura e ciências da religião. O discurso sobre o sagrado ou o transcendente interessa o cientista da religião e este discurso não está ausente das obras literárias, além de se poder ali encontrar comportamentos religiosos apresentados em referência a culturas, sociedades ou simples maneiras de existir. Embora tenha se convencionado chamar a área de estudos de teologia e literatura, muitas vezes o trabalho se realiza na aproximação entre religião e literatura. Não é ruim que seja assim e não há prejuízo neste procedimento. Se é legítimo que a literatura se interesse pelo ser humano religioso e o apresente em suas obras, também é legítimo que os que estudam os fenômenos religiosos o façam a partir e no horizonte de obras literárias.

Aliás, o que precisa estar claro é que a literatura não precisa nem deve, jamais, modificar seu modo de ser ou seu jeito de proceder. É em sendo literatura que ela interessa à reflexão teológica e também ao trabalho do cientista da religião. Instrumentalizada para tornar-se mero meio de divulgação de ideias, ideologias ou teorias, a literatura perde sua especificidade porque se modificaria para ser, simplesmente, forma de um conteúdo outro e previamente estabelecido. Embora seja interessante afirmar que a linguagem literária cativa mais que a científica e, por isso, é melhor veículo catequético, com isso não se diz da importância que a literatura tem ou pode ter na vivência religiosa ou na elaboração teológica.

É fato, no entanto, que a linguagem literária seduz bastante, seja na prosa ou no verso. Mesmo as comunidades religiosas quando querem promover certos momentos de reflexão ou de sensibilização, quando querem prestar algum tipo de homenagem, por exemplo, recorrem a canções, poemas ou outros textos literários. Isso se deve, talvez, ao encantamento, como que uma certa magia mesmo, que envolve a literatura ou dela se origina. Por ser comunicação vital, a literatura fala mais ao coração ou ao vivido das pessoas do que textos científicos ou de orientação religiosa, por mais verdadeiros que estes sejam. Há, sim, na linguagem literária, certo poder de sedução que não se pode negar, mas não será esta a maior razão para aproximá-la do universo teológico. 
Não é meu intuito aqui discutir o parentesco eventual entre a linguagem literária e a linguagem teológica. Algo já foi feito a respeito ${ }^{5}$ e creio que o debate sobre isso pode avançar ainda mais ${ }^{6}$. Insisto ainda uma vez em situar-me do lado da teologia, com as condições e eventuais limites epistemológicos que daí decorrem. Desde este ponto de vista, pergunto qual o interesse teológico no diálogo com o literário. Reconheço que outras questões podem ser apresentadas, com valor e pertinência acadêmicas. Mas minha pergunta é aquela.

\section{HUMANIDADE COMO CENTRO}

Não é sem interesse, por isso, repetir que a literatura é expressão do humano, lugar do humano, revelação do humano, para usar uma palavra do vocabulário teológico. É o humano o foco do literário, em seu discurso sobre sua significação, suas grandezas e problemas, sua vida, decepções e encantamento. Não é propriamente a preocupação de conhecer o humano, terreno próprio das ciências, mas de afirmar o humano, a ele se referir ou o colocar em ação de existência. Radicalmente humana é a literatura e por isso existe em todos os povos e culturas, em maneira plural de afirmar o humano e suas possibilidades praticamente incontáveis de formas de existir. Ainda uma vez, a afirmação de que a literatura tem o antropológico como seu dado fundamental.

Daqui se caminha muito rapidamente para afirmar que também o religioso e o teológico são assim. O estudo das religiões, de sua história, ritos e doutrinas, de forma comparativa ou não, quer ajudar a compreender o ser humano e o conhecimento que produz se soma ao de tantos outros campos da ciência que, também eles, procuram entender o humano e o mundo onde se vive. De certa forma isto também é verdade para a elaboração teológica. A teologia se esforça por conhecer mais e melhor o ser humano e também o conhecimento que ela produz se junta ao dos outros campos de conhecimento. $\mathrm{O}$ enigma humano também se constitui em desafio para o pensamento teológico ${ }^{7}$.

Mas a teologia não é discurso de conhecimento sobre Deus, como diz sua etimologia? A maneira de este conhecimento se relacionar com a compreensão

\footnotetext{
5 Assim por exemplo SPADARO A. La grazia dela parola. Karl Rahner e la poesia. Milano: Jaca Book, 2006.

${ }^{6}$ Assim VILLAS BOAS, A. Teologia e literatura como teopatodiceia: em busca de um pensamento poético teológico. Tese doutoral apresentada na PUC-Rio. Rio de Janeiro, 2013. Também LIMA, A.P; MANZATTO, A. A (re-)descoberta do imaginário no universo teológico: uma reflexão a partir de Adolphe Gesché; Teoliterária, 7, 2014, pp. 250-264.

7 Veja-se GESCHÉ, A. O ser humano. São Paulo: Paulinas, 2003.
} 
do ser humano pode ser um indicativo da pertinência da teologia para o discurso antropológico e para a manutenção de sua caracterização como ciência. Não há dúvidas de que a teologia tem direito a um discurso antropológico porque ela se relaciona com o conhecimento do que significa ser humano neste mundo, porque o discurso sobre Deus se relaciona com o discurso sobre o humano. Talvez, no entanto, o percurso mais importante e significativo seja o inverso.

\section{EPISTEMOLOGIA TEOLÓGICA}

Cabe lembrar aqui os procedimentos epistemológicos da teologia. Ela é discurso a partir da fé sobre a razoabilidade da própria fé. Ou, em outras palavras, é a fé que busca compreender-se. Para isso seus referenciais são, evidentemente, científicos do ponto de vista epistemológico, respondendo às exigências de lógica e rigor próprios do conhecimento científico. As condições e exigências de conhecimento científico lhes são dadas por outros campos de conhecimento e reflexão que não ela, mas tais campos não ditam os conteúdos do conhecimento teológico. Por isso ela se refere fundamentalmente ao dado revelado, haurido da fonte da fé que é Deus mesmo, tal como consta na Escritura, Tradição e Magistério. Não se faz teologia em ambiente cristão sem a aceitação da Revelação de Deus ou seja, sem situar-se em ambiente de fé, porque senão estaríamos em outro procedimento epistemológico.

A Revelação nos é apresentada na Escritura e na Tradição, como lembra a Dei Verbum (9), que precisam ser compreendidas e interpretadas, e aqui se situa o papel do Magistério como luz e guia para esta interpretação. Posto isso, será necessário ter presente que a interpretação permanece como desafio constante para a comunidade crente, sobretudo por sua exigência de atualização. Neste sentido, o trabalho de compreensão da fé nunca está concluído porque ela deve ser significativa para todas as gerações, inclusive as futuras. A Revelação permanece, então, como diálogo constante e atual entre Deus e a humanidade para quem Ele continua se revelando e a quem continua salvando, enquanto esta procura sempre melhor conhecê-lo e amá-lo ${ }^{8}$.

\footnotetext{
8 Por exemplo LIBÂNIO, J. B. Teologia da Revelação a partir da modernidade. São Paulo: Loyola, 1992; ainda THÉOBALD, C. A revelação, São Paulo: Loyola, 2006.
} 


\section{LITERATURA E BÍBLIA}

A Escritura precisa ser lida, assim como a Tradição. Esta não está nunca terminada porque é a linha que liga cada geração aos acontecimentos fundantes da fé; aquela, carece de compreensão. A literatura tem ajudado muito a melhor compreender os textos bíblicos desde o momento em que se passou a vê-los como obras literárias. Sim, a Escritura é obra de literatura respondendo ao trabalho de elaboração redacional de seu conteúdo. Isto é conhecido há muito tempo, mas apenas recentemente as categorias e ferramentas dos estudos literários passaram a ser aplicados na leitura da Escritura, e isto trouxe nova luz para sua compreensão. Vislumbra-se o trabalho do redator não como mero arranjador das histórias ou passagens, mas como artista que compõe uma obra literária seguindo as formas e procedimentos próprios de fazê-lo ${ }^{9}$ A compreensão da significação daqueles textos pode ser mais profunda e detalhadamente elaborada, exatamente para iluminar melhor a fé e a vida do crente. Em outras palavras, os procedimentos literários muito ajudaram na leitura e compreensão da Escritura e, fato inegável, isso deriva da aproximação entre teologia e literatura. Em certo sentido, o trabalho de leitura da Escritura com os métodos literários é fruto deste diálogo entre elas.

Se de um lado isso permite avançar na leitura da Escritura para ultrapassar o método fundamentalista, que lê o texto ao pé da letra, por outro lado permanece a convicção de que os textos bíblicos continuam normativos para a elaboração teológica e a compreensão da fé. Não é porque a Escritura é uma composição literária que ela perde sua característica de Revelação de Deus. $\mathrm{O}$ fato de ser composta e redigida de maneira semelhante a outras peças literárias não a torna, simplesmente, obra literária de valor teológico igual a qualquer outro texto de literatura. O caráter da Escritura permanece como norma e referência para a afirmação da fé e sua compreensão teológica. $O$ mesmo se dá com a leitura da Tradição, e o papel do Magistério é este, de guiar a compreensão que se elabora de uma e outra.

Aqui o interesse daquela questão que formulei anteriormente: qual o interesse da literatura para a teologia se tudo está na Escritura e na Tradição? Não se pode fazer teologia prescindindo do literário? Efetivamente se fez assim

${ }_{9}$ Assim em, por exemplo, ALETTI, N.; GILBERT, M.; MIES, F.; SONNET, J-P.; WENIN, A. Bible et littérature; Namur, Lessius, 1999; também WÉNIN, A./ MARGUERAT, D.; ESCAFFRE, B. En torno a los relatos biblicos; Estella: Editorial Verbo Divino, 2005. 
por muitos séculos e parece que a teologia não precisa, mesmo, de recurso a outros textos que não sejam os da Escritura, Tradição e Magistério. Por muitos anos a teologia tem se mantido assim, sem desviar-se de seu caminho de compreender a fé que é professada. E aqui, na atualidade, reconhecem-se os dois caminhos que nasceram do recente diálogo entre teologia e literatura e aos quais já aludimos: aquele de ler a Escritura com as ferramentas de análise literária e aquele de tirar de textos literários elementos para a confissão de fé. No primeiro, a literatura ajuda a compreender os textos bíblicos auxiliando, assim, a entender melhor a Revelação de Deus. O segundo, mais próximo do discurso religioso, foca a possibilidade de o literário ajuntar conteúdos à afirmação de fé. Creio, no entanto, que a questão pode ser pontuada de uma outra maneira e, então, mostrar toda sua pertinência.

\section{REVELAÇÃO E LITERATURA}

Constitui convicção de fé cristã que Deus se revela na História. Dito de outra forma, a história humana é o lugar do encontro do ser humano com Deus pelo simples fato de o ser humano existir na história. História é o lugar do humano e se Deus quer a ele se revelar, precisa entrar na história porque não haverá condições de o humano encontrá-lo e conhecê-lo senão ali onde ele vive sua vida. Não há humano sem história. Tal compreensão, hoje tão evidente, não se deu sem os avanços proporcionados pelo Concílio Vaticano II que fez passar de uma teologia essencialista para uma teologia com características históricas.

Os recentes estudos exegéticos nos ajudaram a compreender que na Bíblia não encontramos fatos históricos brutos, mas histórias que são narradas sobre acontecimentos históricos. Estas narrações não têm o objetivo de dar a conhecer aos leitores os fatos tais como aconteceram, mas sim o significado que tiveram na existência concreta das pessoas, inclusive seus autores ${ }^{10}$. Daí que o interesse exegético não está em verificar a historicidade da narrativa, que talvez seja possível, mas em compreender seu significado, que sempre será necessário. Por isso, ainda que narrando histórias que não são verídicas do ponto de vista historiográfico, a Bíblia apresenta formas de compreensão da história que são leituras de sua significação, sempre verdadeiras porque humanas e pertinentes à história humana. Ou, dito de outra maneira, o que está em jogo aqui não é a descrição do acontecimento, mas a afirmação da verdade do humano que aquela versão do acontecimento apresenta. Até porque, repita-se, não há fatos brutos

${ }^{10}$ São clássicos os textos de P. Ricoeur a respeito. Veja-se por exemplo RICOEUR, P. Tempo e narrativa, 3. Vols. São Paulo: Martins Fontes, 2011. 
na história, eles sempre precisam de interpretação, ou seja, precisam ser significativos $^{11}$. O que não significa nada é como se não tivesse acontecido e por isso a narrativa aponta para a significação mais que para o fato. Daí que a história e seu significado são afirmados pelas histórias que se narram ou que a eles aludem. De certa forma, o Deus que se revela na História, se revela nas histórias que são contadas sobre sua ação.

Acrescente-se a isso um segundo elemento, não menos importante. Constitui, igualmente, convicção de fé de que Deus se Revela em categorias humanas. Deus se revela no humano que é sua imagem e semelhança, como afirma o livro do Gênesis, de maneira que quanto mais humano, mais semelhante a Deus. Tanto é verdade que Deus que a plenitude de sua Revelação está em Jesus de Nazaré, o Verbo Encarnado. Deus se fez homem e é este o caminho para conhecê-lo e paraa salvação da humanidade.

Mais do que uma constituição física, o ser humano é uma constituição histórica. Sua humanidade não é simplesmente corporal, mas histórica, o que significa que é corpo situado em determinado contexto, época, cultura, língua, etc. A Revelação de Deus assume estas características não porque Deus, eventualmente, não pudesse revelar-se de outra maneira, mas porque o ser humano não compreenderia esta Revelação se ela não fosse realizada nas categorias de humanidade $^{12}$. Compreender as referências à Revelação em sua historicidade não significa ater-se à verdade historiográfica do que é narrado, mas aos contextos de significação onde as histórias que se referem àquela situação foram compostas, narradas, escritas. Deus que fala ao humano o faz através de sinais e eventos que o humano pode compreender e que serão, por isso, sempre históricos. Mais uma vez, o Deus que se revela na História o faz em situações de humanidade.

São estas situações de humanidade que constituem a literatura. Ela não se refere a outra coisa que não seja o humano, já o dissemos. Se Deus se revela em humanidade, se revela no humano histórico, no sentido historiográfico ou literário $^{13}$. Ele se revela nas histórias que são narradas sobre o humano

\footnotetext{
${ }^{11}$ Veja-se, além do citado, RICOEUR, P. O conflito das interpretações, Rio de Janeiro: Imago, 1978.

12 Além do citado, veja-se THÉOBALD, C. Dans les traces... de la Constitution Dei Verbum du Concile Vatican II. Paris: Cerf, 2009.

13 GESCHÉ, A. La théologie dans le temps de l'homme, Littérature et Révélation. In VERMEYLEN, J. (dir.), Cultures et théologies em Europe: jalons pour un dialogue. Paris: Cerf, 1995, pp. 109-142.
} 
afirmando não necessariamente a verdade do fato em si, mas do significado humano que ali está. Dizer que Deus se revela no humano é, de certa forma, dizer que ele se revela no humano existente e no humano pensado, naquele que é e naquele que pode ser ou poderia ter sido. Aqui já não tem importância se o fato narrado é histórico ou é ficção, porque um e outro aludem para o que o humano significa, e este é Revelação de Deus. Claro que aqui, pelo procedimento teológico, será necessário ainda conferir se este humano está em concordância com a Escritura, sobretudo a apresentação de Jesus de Nazaré que ali é feita. Mas não se trata se submeter a literatura às afirmações dogmáticas, mas sim de permitir-lhe iluminar a compreensão que se faz do humano e, por este caminho, chegar a um conhecimento mais apurado de Deus.

\section{CONCLUSÃO}

A aproximação entre teologia e literatura e o diálogo estabelecido entre elas pode ser mais que significativo para a teologia. Não será simples desvio de reflexão, que se poderia fazer mais diretamente se unicamente derivada da Escritura ou de outros textos teológico-doutrinais. A literatura constitui uma referência que possibilita caminhar no conhecimento de Deus pelo conhecimento do humano. Mais do que afirmar, como Agostinho, a distância entre um e outro, caberia lembrar o dito evangélico: Felipe, quem me viu, viu o Pai. O humano histórico onde Deus se revela está presente também na literatura, inclusive nos textos de ficção. E se a teologia caminhou muito tempo sem ela e conseguiu conhecer algo de Deus e do humano, muito mais e com mais facilidade poderá caminhar neste conhecimento tendo a literatura como companheira de jornada.

\section{REFERÊNCIAS}

ALETTI, N.; GILBERT, M.; MIES, F.; SONNET, J-P.; WENIN, A. Bible et littérature. Namur, Lessius, 1999.

ELIADE, M. O sagrado e o profano. A essência das religiões. São Paulo: Martins Fontes, 1992.

GESCHÉ, A. O ser humano. São Paulo: Paulinas, 2003.

GESCHÉ, A. La théologie dans le temps de l'homme, Littérature et Révélation. In: VERMEYLEN, J. (dir.), Cultures et théologies em Europe: jalons pour un dialogue. Paris: Cerf, 1995, pp. 109-142. 
LIBÂNIO, J. B. Teologia da Revelação a partir da modernidade. São Paulo: Loyola, 1992.

LIMA, A.P; MANZATTO, A. A (re-)descoberta do imaginário no universo teológico: uma reflexão a partir de Adolphe Gesché. Teoliterária, 7, 2014, p. 250-264.

${ }^{1}$ MANZATTO, A. Pequeno panorama de teologia e literatura. In: MARIANI, C.B.; VILHENA, M.A, (Orgs.). Teologia e arte. São Paulo: Paulinas, 2010, p. 87-98.

MANZATTO, A. Teologia e literatura. São Paulo: Loyola, 1994.

OTTO, R. O sagrado, os aspectos irracionais do divino e sua relação com o racional. São Leopoldo-Petrópolis: Sinodal-Vozes, 2007.

RICOEUR, P. O conflito das interpretações. Rio de Janeiro: Imago, 1978.

RICOEUR, P. Tempo e narrativa. 3. Vols. São Paulo: Martins Fontes, 2011.

SPADARO A. La grazia dela parola. Karl Rahner e la poesia. Milano: Jaca Book, 2006.

THÉOBALD, C. A revelação. São Paulo: Loyola, 2006.

THÉOBALD, C. Dans les traces... de la Constitution Dei Verbum du Concile Vatican II. Paris: Cerf, 2009.

TOUTIN, A. Teologia y literatura: Hitos para um diálogo; Anales de la Facultad de Teologia 3; Suplementos a Teologia y Vida; Santiago: Pontifícia Universidad Católica de Chile, 2011.

VILLAS BOAS, $A$. Teologia e literatura como teopatodiceia: em busca de um pensamento poético teológico. Tese doutoral apresentada na PUC-Rio. Rio de Janeiro, 2013.

WÉNIN, A./ MARGUERAT, D.; ESCAFFRE, B. En torno a los relatos bíblicos. Estella: Editorial Verbo Divino, 2005.

YUNES, E. O que é a ALALITE?. Teoliterária 2 (2011), pp. 206-208.

YUNES, E; ROCHA, A; CARVALHO G. (Orgs.), Teologias e Literaturas: considerações metodológicas. São Paulo: Fonte Editorial, 2011. 